\title{
6 Quantitative hydrological preferences of benthic 7 stream invertebrates in Germany
}

$8 \quad$ Kakouei, Karan ${ }^{1}$; Kiesel, Jens ${ }^{2}$; Kail, Jochem ${ }^{3}$; Pusch, Martin T. ${ }^{4}$; Jähnig, Sonja C. ${ }^{5}$

9

10

11

DOI

\subsection{6/j.ecolind.2017.04.029}

\section{Original publication date}

15 May 2017 (Available online)

\section{Document version}

Accepted manuscript

Published in

Ecological Indicators

\section{Citation (Vancouver)}

Kakouei K, Kiesel J, Kail J, Pusch MT, Jähnig SC. Quantitative hydrological preferences of benthic stream invertebrates in Germany. Ecological Indicators. 2017;79:163-72.

\section{Author affiliation}

1: Department of Ecosystem Research, Leibniz-Institute of Freshwater Ecology and Inland Fisheries (IGB), Justus-Von-LiebigStr. 7, 12489 Berlin, Germany. (D) https://orcid.org/0000-0001-8665-6841

2: Department of Ecosystem Research, Leibniz-Institute of Freshwater Ecology and Inland Fisheries (IGB), Justus-Von-LiebigStr. 7, 12489 Berlin, Germany. (D) https://orcid.org/0000-0002-4371-6434

3: Department of Aquatic Ecology, University of Duisburg-Essen, Universitätstraße 5, 45141 Essen, Germany.

4: Department of Ecosystem Research, Leibniz-Institute of Freshwater Ecology and Inland Fisheries (IGB), Justus-Von-LiebigStr. 7, 12489 Berlin, Germany.

5: Department of Ecosystem Research, Leibniz-Institute of Freshwater Ecology and Inland Fisheries (IGB), Justus-Von-LiebigStr. 7, 12489 Berlin, Germany. (D) https://orcid.org/0000-0002-6349-9561 
Current knowledge regarding the flow preferences of benthic stream invertebrates is mostly based on qualitative data or expert knowledge and literature analysis. These established flow preferences are difficult to use in predictions of the effects of global change on aquatic biota. To complement the existing categories, we performed a large-scale analysis on the distribution of stream invertebrates at stream monitoring sites in order to determine their responses to various hydrological conditions.

We used 325 invertebrate surveys from environmental agencies at 238 sites paired to 217 gauges across Germany covering a broad range of hydrological conditions. Based on these data, we modelled the respective probabilities of occurrences for 120 benthic invertebrate taxa within this hydrological range using hierarchical logistic regression models.

Our analyses revealed that more than one-third of the taxa (18-40\%) can be considered as ubiquitous and having a broad hydrological tolerance. Furthermore, 22-41\% of the taxa responded to specific ranges of flow conditions with detectable optima. "Duration high flow event" represented the flow parameter that correlated best with the abundance of individual taxa, followed by "rate of change average event", with 41 and $38 \%$ of the taxa showing a peak in their probability of occurrence at specific ranges of these metrics, respectively. The habitat suitability for these taxa may be potentially affected by global change-induced hydrological changes.

Quantified hydrological traits of individual taxa might therefore support stream management and enable the prediction of taxa responses to flow alteration. The hydrological traits of stream benthic invertebrates may be used in forecasting studies in central Europe, and the methods used in this study are suitable for application in other regions with different flow regimes.

\subsection{Introduction}

Hydraulic conditions are key habitat variables for all biota living in running waters and result from the interaction between river morphology and discharge or flow. Benthic invertebrates show high biodiversity in streams and rivers, have been shown to include indicator species sensitive to flow conditions, occupy a central position in the functioning of river ecosystems, and display some fascinating adaptations to flowing waters, e.g., in terms of life history, nutrition, respiration, or behavioral and morphological characteristics (Bellard et al., 2012; Lytle and Poff, 2004; Poff et al., 2007; Statzner et al., 1988). However, quantitative empirical knowledge on the flow requirements or preferences of lotic benthic invertebrates is limited but is essential (i) to assess the effects of hydrological alterations, e.g., due to global change or water uses, and (ii) to identify environmental flow regimes that aim to preserve the ecological integrity of river ecosystems (Bunn and Arthington,

68 2002; Poff and Zimmerman, 2010). 
There are three main approaches to assessing flow preferences. First, they are usually assessed based on literature reviews and/or expert knowledge and described at nominal (e.g., "generalist", "lentic" or "lotic") or ordinal scales (e.g., "limnobiont" to "rheobiont") (Schmidt-Kloiber and Hering, 2015) and have already been collated for many taxa and compiled in databases such as the freshwaterecoloy.infodatabase (Schmidt-Kloiber and Hering, 2015). Such descriptive classifications of invertebrate flow preferences are suitable and widely used to compare the flow trait composition of different sampling sites (Armanini et al., 2011). However, due to their qualitative nature, they are less suited to assess, model and predict the effects of flow changes that are described in quantitative terms (e.g., discharge changes due to global change). Second, the hydraulic preferences of invertebrates have already been described in semi-quantitative terms in several studies by recording species' probability of occurrence and relating it to near-bed shear stress measured using FST-hemispheres (Schmedtje, 1995; Statzner et al., 1988). However, data requirements and computational time make it infeasible to map or model the hydraulic conditions at larger than reach scales (e.g., for whole river networks) to apply such hydraulic preferences, e.g., for their application in catchment or larger scale species distribution models. Moreover, the hydraulic shear stress recorded for a specific discharge only partly reflects the complex relationship between changing flow conditions over time, since it effects species throughout different life stages and finally determines reproductive success and hence, the presence or absence of individual invertebrate species. Third, flow preferences can be based on qualitative discharge measurements, which can be summarized into typical flow or hydrological regimes when analyzed over time. It has been shown that the flow regime strongly influences ecological processes and that changes in the abundance and distribution of aquatic invertebrates are caused, in part, by flow alterations (Brooks et al., 2011; Poff and Zimmerman, 2010). In contrast to shear-stress data, longterm discharge time series (gauging data) are readily available at large spatial scales. Additionally, these data are useful for statistical modelling and for its large-scale upscaling, e.g., to predict the effects of discharge changes due to global change. Despite this clear relationship between the hydrological conditions and biota, few studies have used hydrological data to quantify the flow preferences of benthic invertebrates in rivers. Among these, most studies represent specific case studies and reviews on flow alteration and associated ecological processes (Dunbar et al., 2010a; Monk et al., 2007; Monk et al., 2006; Poff and Zimmerman, 2010), with a prevailing focus on the community structure (Brooks et al., 2011; Death, 2008b; Konrad et al., 2008; Principe et al., 2007) preferentially on individual taxa (Armanini et al., 2011).

We aimed to quantitatively determine the flow preferences of lotic invertebrates - thereby defining "hydrological traits" for central European rivers by analyzing existing hydrological and biomonitoring data. More specifically, we (i) investigated whether invertebrates show a clear response and have an optimum along the gradient of different hydrological variables and hence have specific hydrological 
traits at all and (ii) aimed to quantify the hydrological thresholds at which species abundance and presence sharply change.

\subsection{Methods}

\subsubsection{Datasets and pairing biomonitoring sites with gauging stations on the river network}

We gathered and analyzed two independent, already existing long-term datasets from Germany: (i) daily hydrological data (gauging data) and (ii) results from benthic invertebrate surveys conducted by regional water managers in German rivers. Our dataset covers a wide range of hydrological conditions in Germany, including streams and rivers in the northern lowlands, central lower-mountain areas, and Alpine region of southern Germany.

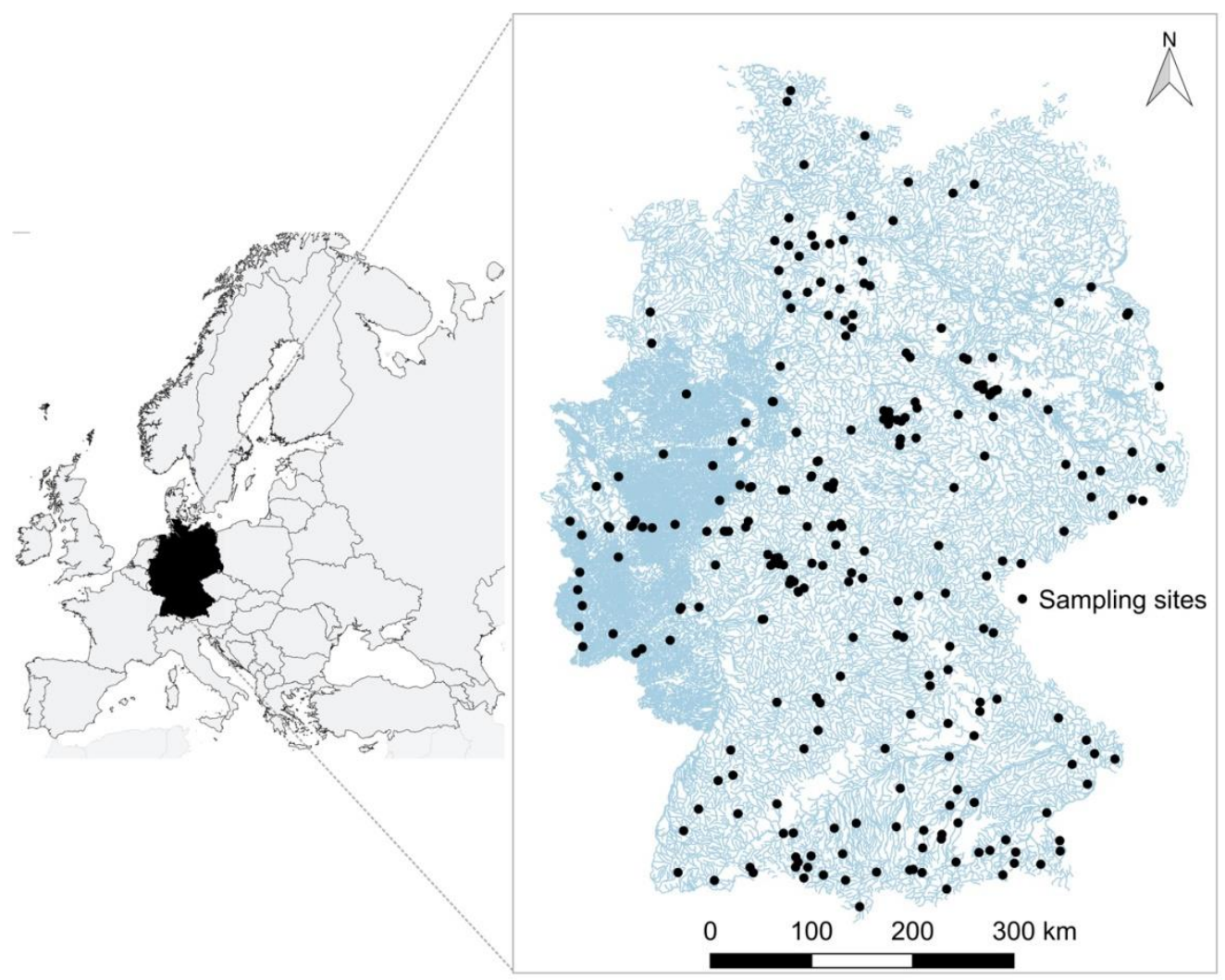

Figure 1 The locations and distribution of sampling sites in the German river network. The gauging stations are not shown as they are too close to sampling sites for being distinguishable on this scale Using the German national flow gauge network and the geographical coordinates of the benthic invertebrate sampling sites, we searched for gauging stations located in the same river reach as at least one biomonitoring site. As the locations of biomonitoring sites did not usually match those of the gauging stations, they were assigned to the nearest station (DeWeber and Wagner, 2014) when the following criteria were met: (i) having no tributaries in between and (ii) located within 
122 a maximum distance of $12 \mathrm{~km}$ from the paired gauging station. This pairing resulted in 371

123 invertebrate surveys from 238 sites paired to 217 gauging stations (Figure 3). To consider the effect of

124 distance on discharge, the discharge data from the gauging station was recalculated for the sampling

125 sites according to the ratio between the catchment size at the biomonitoring site and at the paired 126 gauge.

127 The biological dataset included abundance data for benthic invertebrate taxa that had been sampled in

128 either spring or summer between 2004 and 2013 according to the currently used standard

129 biomonitoring protocols. All sites were in a good or high ecological status according to the EU Water

130 Framework Directive. We analyzed the hydrological preferences of 120 taxa that occurred in at least

131 eight sites for each season (spring and summer). Rare taxa with an abundance of fewer than three

132 occurring in fewer than eight sampling sites were excluded from the dataset because such sparse data

133 do not allow statistical analysis (Heino and Soininen, 2010; Leigh and Datry, 2016). The taxonomic

134 resolution was the species level (111 taxa), while nine taxa were only identified to the genus level

135 (Supplementary Table ST1). The most frequent orders were Trichoptera (43 taxa), Ephemeroptera

136 (25), Coleoptera (12) and Diptera (12) (Table 2). Prior to all analyses, the abundance data were log

$137(\mathrm{x}+1)$-transformed.

Table 1 Number of taxa per systematic unit analysed in this study

\begin{tabular}{lcc}
\hline Taxon & Number of species & Number of genera \\
\hline Trichoptera & 41 & 2 \\
Ephemeroptera & 24 & 1 \\
Coleoptera & 11 & 1 \\
Diptera & 7 & 5 \\
\hline Crustacea & 5 & - \\
\hline Plecoptera & 3 & 1 \\
\hline Gastropoda & 4 & - \\
\hline Turbellaria & 3 & - \\
\hline Oligochaeta & 3 & - \\
Bivalvia & 2 & - \\
\hline Megaloptera & 2 & - \\
\hline Odonata & 2 & - \\
\hline Hirudinea & 2 & \\
\hline Heteroptera & 1 & $\mathbf{1 2 0}$ \\
\hline Total number of taxa & & \\
\hline
\end{tabular}

138 
Since the addition of pseudo-absences is strongly recommended when modelling species preferences and distributions (Vaughan \& Ormerod, 2005; Lobo \& Tognelli, 2011) we added absence data for species at specific sites. Instead of randomly generated absence data (Lobo and Tognelli, 2011; VanDerWal et al., 2009), we preferentially generated absence data using a semi-random stratified approach, considering the stream type (Schmedtje et al., 2000) of the sampling sites according to their common environmental and hydromorphological characteristics. Sites with absences were selected based on two criteria: (i) having the same stream type as sites where the taxa were already recorded and (ii) being located in the same region/federal state as the present sites. These two criteria ensured the exclusion of sites representing inappropriate habitat conditions for the occurrence of taxa. All sites meeting these criteria were added as pseudo-absences to the analysis.

\subsubsection{Computation and pre-selection of hydrological metrics}

There are 171 hydrological metrics known as Indicators of Hydrologic Alteration (IHA) that are ecologically relevant and can be calculated based on daily discharge data, describing the duration, frequency, timing, magnitude, and rate of flow events (Olden and Poff, 2003). These metrics were calculated using discharge data from the 12-month period prior to the date of the biological sampling (e.g., for a macroinvertebrate sample from 12.06.2012, flow data between 13.06.2011 and 12.06.2012 were considered). This period has been shown to best describe the effects of hydrological conditions on benthic invertebrates (Leigh and Datry, 2016). Twenty metrics were excluded due to the need for longer periods of discharge data, resulting in 151 metrics for further analysis. There was no significant gap (i.e., missing values for more than 5 days) in the discharge data for any of the sampling sites. Missing discharge data were filled in for individual gaps according to the trends before and after failures and by comparing trends with the data from nearby gauge(s) for which pairwise correlations exceeded the reliable threshold of $|r|>0.5$ (Kennard et al., 2010; Leigh, 2016). All flow metrics were computed using the R package EflowStats (Archfield et al., 2014; Henriksen et al., 2006).

We aimed to select at least one metric from each of the five flow regime categories (duration, frequency, timing, magnitude and rate) to minimize redundancies prior to the development of the hierarchical logistic regression models (see below). A pairwise collinearity test and a principal component analysis facilitated the selection among the 151 hydrological metrics using data from the 217 paired gauges. When pairwise correlations exceeded the sensitive threshold of $|r|>0.7$ (Dormann et al., 2013), and hence redundancy occurred, the metric with the lower loading on the most significant principal component axis was removed from the list.

\subsubsection{Temporal and spatial pseudo-replication}

It was necessary to analyze temporal and spatial pseudo-replication because some sampling sites were

172 paired with the same gauging station or may be flow-connected (Hale et al., 2016b). To avoid temporal pseudo-replication, sampling sites paired to the same gauging 
station and with overlapping 12-month periods were considered temporally dependent, and only the site located nearest to the gauging station was included in the analysis. This resulted in removing 46 of the 371 benthic invertebrate sampling sites.

We further tested for spatial autocorrelation resulting in pseudo-replication among sites that are longitudinally flow-connected (Hale et al., 2016b). However, due to the large spatial scale of this study, less than five percent of the biomonitoring sites were flow-connected. To test the spatial autocorrelation and detect sites with pseudo-replication, we first grouped flow-connected sites and then divided them into several bins with different distance categories among sites. We then calculated the Moran's I autocorrelation coefficient (Gittleman and Kot, 1990) for each hydrological metric of all sites in a group and then for different distance categories. However, Moran's I was not significant for any of the sampling site pairs, and hence none of the sites had to be excluded from the analysis due to spatial autocorrelation.

\subsubsection{Hierarchical logistic regression modelling}

We selected extended Huisman-Olff-Fresco (eHOF) models to quantify the flow traits of benthic invertebrates because they offer a variety of ways to efficiently fit the response data of taxa (Jansen and Oksanen, 2013). Based on the complexity of the biological data, the models were ranked in the following order with increasing empirical evidence for a response of the taxa to the hydrological metrics and evidence for the existence of a hydrological threshold: (I) a flat response over the hydrological gradient, (II) monotone in-/decreasing model: a monotone increasing or decreasing trend with a data-driven optimum at the end or at the beginning, respectively, (III) interval optimum model: an increasing or decreasing trend with a plateau below the upper bound, (IV) symmetrical model: a symmetrical response curve with similar slopes on both sides, and (V) skewed model: a skewed response curve with a steeper slope toward the gradient end (Huisman et al., 1993a; Jansen and Oksanen, 2013) (Table 3).

These models enable the determination and identification of taxa preferences for environmental conditions, e.g., min./max./optimum values for individual taxa. The set of five hierarchical models can be fitted to the observations and describe the response pattern over the environmental gradient with logistic and non-linear regression techniques (Huisman et al., 1993a; Jansen and Oksanen, 2013).

Covering a wide range of hydrological conditions across Germany, the probability of occurrence for individual taxa was determined and quantified by sorting the log-transformed abundance data along the gradient of each hydrological metric. The most adequate model type that best fitted the observations was selected according to its deviance from the log-likelihood of the predictions and an Akaike test (Akaike information criterion; AIC). The purity of the selected model type was quantified via bootstrapping with 100 re-sampling events (Supplementary material). The bootstrapping approach 
Table 2 Description of eHOF models (according to Huisman et al., 1993; Jansen and Oksanen, 2013)

\begin{tabular}{ll}
\hline eHOF model type & Description \\
\hline Flat response model (I) & A flat response over a hydrological gradient \\
schemes
\end{tabular}
hydrological gradients

Based on the individual model outcomes, the response shape and the highest probability of occurrence along the hydrological range, we evaluated the importance of each metric for the whole taxa pool. To analyze the taxa responses along the range of hydrological gradients, the ranges of each metric were divided into quartiles. For each taxon, the quartile was recorded in which the optimum gradient value is reached (i.e., where the response is strongest). The optimum is an interval for taxa with an interval optimum model; therefore, their optimum gradient value might be affiliated with two or more quartiles. Prior to this analysis, we excluded taxa assigned to flat response and monotone in/decreasing models, as they tolerate a wide range of hydrological conditions and an optimum value cannot be determined.

\subsubsection{Hydrological thresholds}

The eHOF models provide information on the shape of taxa responses along the hydrological gradients. Using this information, we identified hydrological thresholds (inflection points), where the maximum change occurs in taxa responses when moving along the hydrological gradient. These points 225 can be detected on either the increasing or decreasing limb of the "interval optimum", 
"symmetrical" and "skewed" models. All statistical analyses were carried out in R 3.2.3 (R

227 Development Core Team, 2016).

Table 3 Descriptions, calculation procedures, units and temporal aspects of seven IHA metrics further used in this study (according to Olden \& Poff (2003) and references therein).

\begin{tabular}{|c|c|c|c|c|}
\hline $\begin{array}{l}\text { IHA group } \\
\text { (code) }\end{array}$ & IHA metric & Calculation procedure & Unit & $\begin{array}{l}\text { Temporal } \\
\text { aspect }\end{array}$ \\
\hline $\begin{array}{l}\text { Duration of } \\
\text { high flow event } \\
\text { (dh4) }\end{array}$ & $\begin{array}{l}\text { Annual } \\
\text { maximum 30- } \\
\text { day } \\
\text { moving average } \\
\text { flows }\end{array}$ & $\begin{array}{l}\text { Compute the max of } 30 \text {-day } \\
\text { moving average flows and take } \\
\text { the max for each year; take the } \\
\text { mean of these values. These } \\
\text { values were log-transformed for } \\
\text { use in the modelling approach. }\end{array}$ & $\log \left(\mathrm{m}^{3} / \mathrm{s}\right)$ & Daily \\
\hline $\begin{array}{l}\text { Duration of low } \\
\text { flow event (d19) }\end{array}$ & $\begin{array}{l}\text { Variability in } \\
\text { annual } \\
\text { minimum 30- } \\
\text { day moving } \\
\text { average flows }\end{array}$ & $\begin{array}{l}\text { Compute the standard deviation } \\
\text { of the yearly min } 30 \text {-day moving } \\
\text { averages; multiply by } 100 \text { and } \\
\text { divide by the mean of the yearly } \\
\text { min } 30 \text {-day moving averages }\end{array}$ & $\%$ & Daily \\
\hline $\begin{array}{l}\text { Frequency of } \\
\text { high flow event } \\
\text { (fh9) }\end{array}$ & $\begin{array}{l}\text { Flood } \\
\text { frequency }\end{array}$ & $\begin{array}{l}\text { Compute the number of flow } \\
\text { events with flows above the } 75 \% \\
\text { exceedance value for the full } \\
\text { flow record; take the average } \\
\text { number of events per year }\end{array}$ & 1/year & Annual \\
\hline $\begin{array}{l}\text { Frequency of } \\
\text { low flow event } \\
\text { (fl2) }\end{array}$ & $\begin{array}{l}\text { Variability in } \\
\text { low pulse count }\end{array}$ & $\begin{array}{l}\text { Compute the standard deviation } \\
\text { of the average number of flow } \\
\text { events per year below the } 25 \text { th } \\
\text { percentile for the full flow } \\
\text { record; multiply by } 100 \text { and } \\
\text { divide by the average number of } \\
\text { flow events }\end{array}$ & $\%$ & Annual \\
\hline $\begin{array}{l}\text { Magnitude of } \\
\text { low flow event } \\
(\mathrm{ml} 17)\end{array}$ & Base flow & $\begin{array}{l}\text { Compute mean annual flow, } \\
\text { compute the min of a } 7 \text {-day } \\
\text { moving average annual flow and } \\
\text { divide by the mean annual flow; } \\
\text { calculate the mean of those ratios }\end{array}$ & Dimensionless & Annual \\
\hline $\begin{array}{l}\text { Rate of change } \\
\text { in average } \\
\text { event (ra2) }\end{array}$ & $\begin{array}{l}\text { Variability in } \\
\text { rise rate }\end{array}$ & $\begin{array}{l}\text { Compute the standard deviation } \\
\text { of positive flow changes for the } \\
\text { full flow record, multiply by } 100 \\
\text { and divide by the mean change in } \\
\text { rising flows }\end{array}$ & $\%$ & Daily \\
\hline
\end{tabular}

Timing of average flow Constancy Compute constancy from the Colwell (1974) matrix Dimensionless Daily event (ta1) 

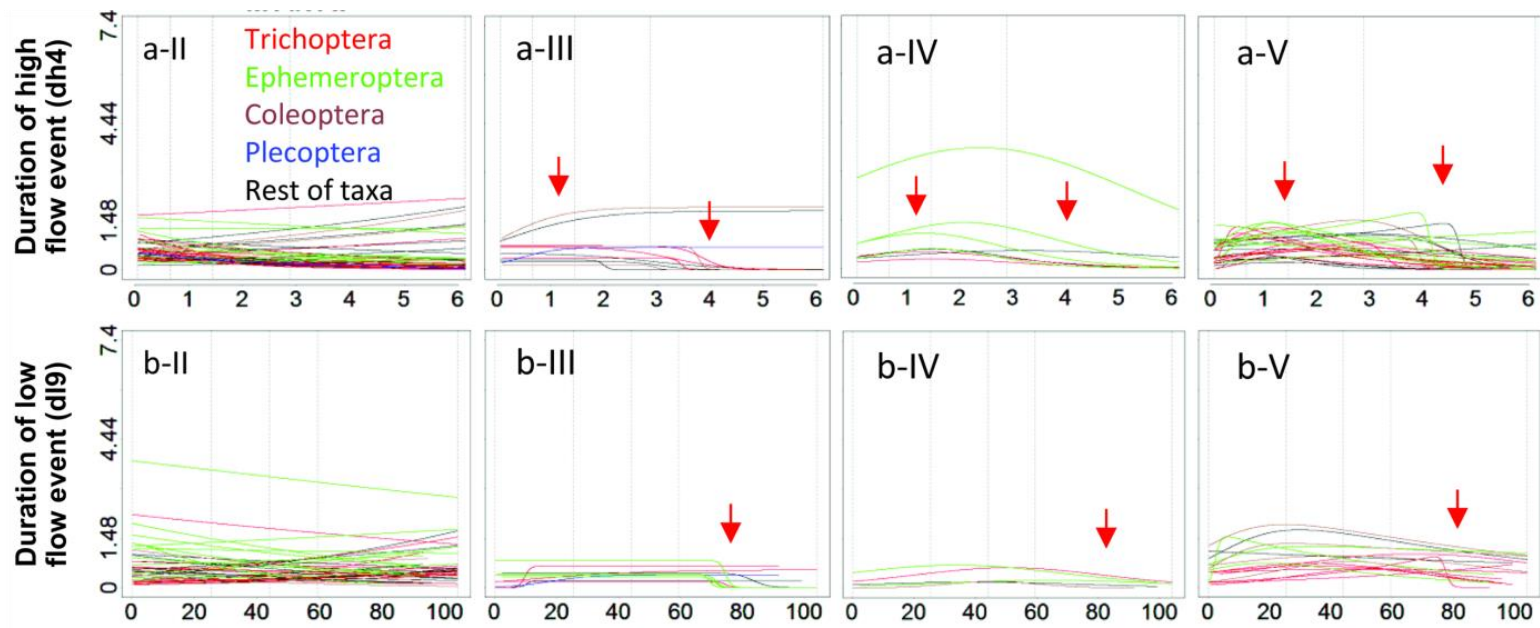

$b-V$
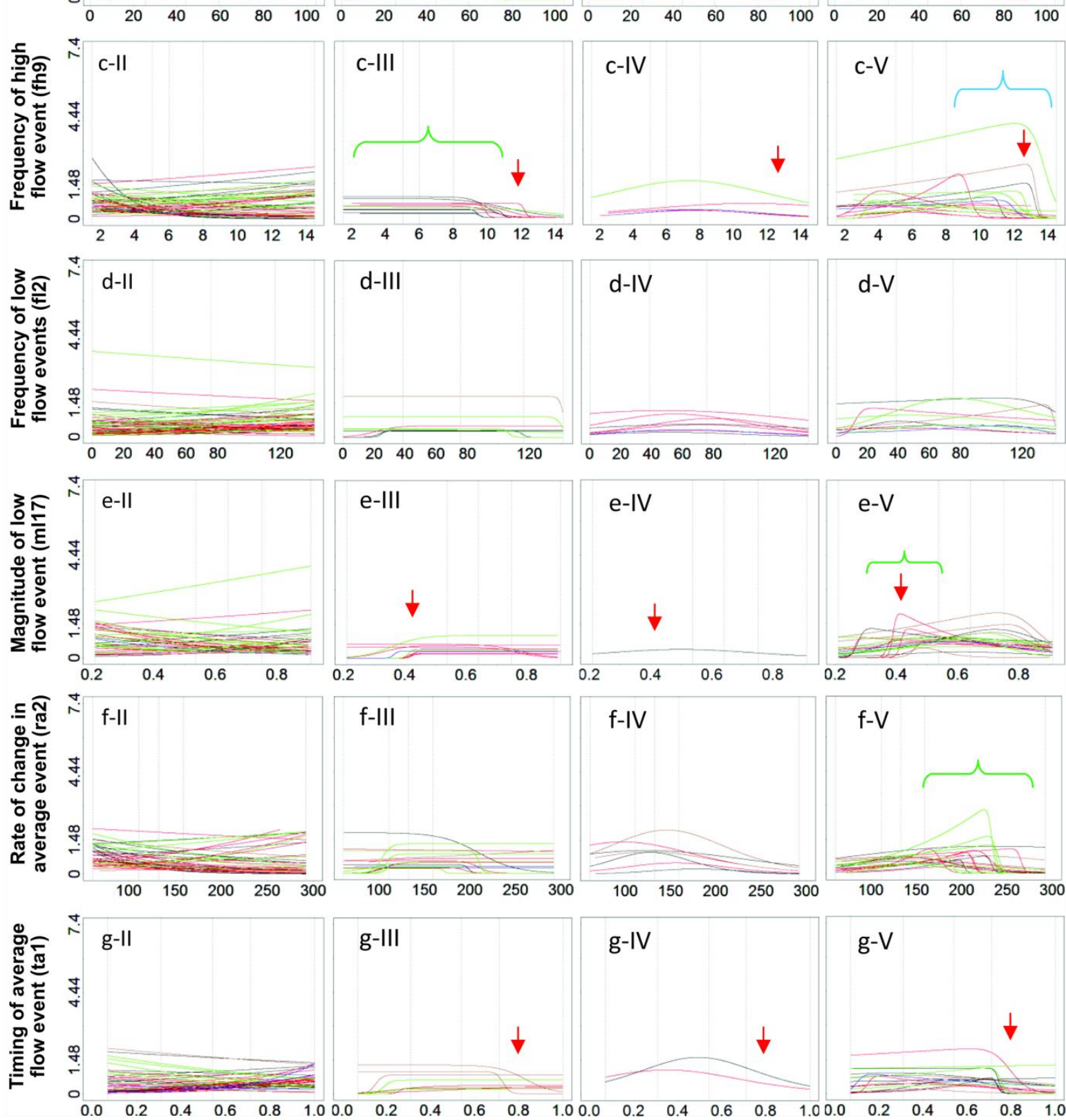

229 Figure 2 Results of models selected for all taxa among all metrics. Rows are separated according to 230 the seven IHA metrics (a to g), columns are separated according to eHOF model types. (c) $(1)\left(\mathrm{F}_{\mathrm{BY}}\right.$ The $\mathrm{x}$-axis represents the gradient of the respective hydrological metrics, and the $\mathrm{y}$ - 
axis is the probability of occurrence of the taxa, which is based on log-transformed abundance data. Quartiles are separated by gray dashed lines, and different colors represent orders. While taxa with the eHOF model types of "interval optimum", "symmetrical" and "skewed" have preferences for specific ranges of hydrological values, taxa with a "flat response" model tolerate wide ranges of hydrological conditions and exhibit no response along the hydrological gradient. The plots of "flat response" models were excluded from this figure due to limited space and the simplicity of this model. The red arrows mark thresholds where the probability of taxa occurrence drastically decreases, and green and blue brackets mark gradient ranges that are preferred by taxa.

\subsection{Results}

\subsubsection{Taxa responses to hydrological metrics}

The following seven metrics (Table 4) remained after the pairwise collinearity test: "Duration of high flow event" (dh4), "duration of low flow event" (d19), "frequency of high flow event" (fh9), "frequency of low flow event" (fl2), "magnitude of low flow event" (ml17), "rate of change in average event" (ra2) and "timing of average flow event" (ta1; Colwell, 1974). Figure 4 shows the results of the models selected for all taxa among all metrics.

The invertebrate taxa responded most strongly to dh4 (duration of high flow event) and ra2 (rate of change in average event), having the lowest share of flat response and monotone in-/decreasing models.

The flat response model was selected for $18-40 \%$ of the taxa, depending on the hydrological metric (Figure 5). The share of taxa showing a monotone increase or decrease along the gradient of the seven hydrological variables was $35-53 \%$. The symmetrical model was the least often selected model among all metrics, selected, on average, for $4 \%$ of the taxa (Figure 5).

\subsubsection{Taxa responses along the range of hydrological gradients}

23-41\% of all 120 taxa show clear preferences along the ranges of the seven hydrological metrics. The three eHOF model types "interval optimum", "symmetrical" and "skewed" allow the determination of the positions of optimum values for taxa (Figure 6). The lowest proportion of taxa responding to specific ranges of a hydrological metric was to fl2 (frequency of low flow event), and the highest proportion was for dh4 (duration of high flow event).

Taxa occurrences according to the recorded quartile of optimum values varied among metrics (Figure 6). The highest fraction of taxa with high occurrence probabilities in the first quartile were found for ml17 (magnitude of low flow event, $34 \%$ of taxa) and ta1 (timing of average flow event, $42 \%$ of taxa), i.e., taxa occurred more often when low flow events did not last long or when flow events were not highly constant, respectively. The last quartile ranked highest for fh9 (frequency of 
high flow event, $33 \%$ of taxa) and ra2 (rate of change in average event, $38 \%$ of taxa), i.e., taxa occurred more often when a greater number of flow events were recorded with flows above the 75 percent exceedance value for the entire 12-month period or taxa occurred more often with a higher variability in the rise rate, respectively.

269

270

271

272

273

274

275

276

277

278

279

280

281

282

Taxa exhibit peak responses to values lower than the median for fl2 (frequency of low flow event, 61 $\%$ ), ta1 (timing of average flow event, $58 \%$ ) and ml17 (magnitude of low flow event, $57 \%$ ) (Figure 6). Optimal responses were found for values higher than the median for ra2 (rate of change in average event, $63 \%$ ), fh9 (frequency of high flow event, $59 \%$ ) and dh4 (duration of high flow event, $51 \%$ ). Approximately equal proportions of taxa have peak preferences to either higher or lower median values for both metrics belonging to the indicators of hydrologic alteration category of duration ( $\mathrm{dh} 4$, d19); however, the preferences for quartiles differ significantly for all other categories (Figure 6).

Taxa responding according to the monotone in-/decreasing model show either a positive or a negative trend in occurrence probabilities. The two metrics of dh4 and ra2 (duration of high flow event: $73 \%$ and rate of change in average event: $71 \%$ ) had the highest share of negative trends (Table 5), i.e., a high proportion of taxa prefer low values along the gradient of maximum moving average flows or variability in rise rate.

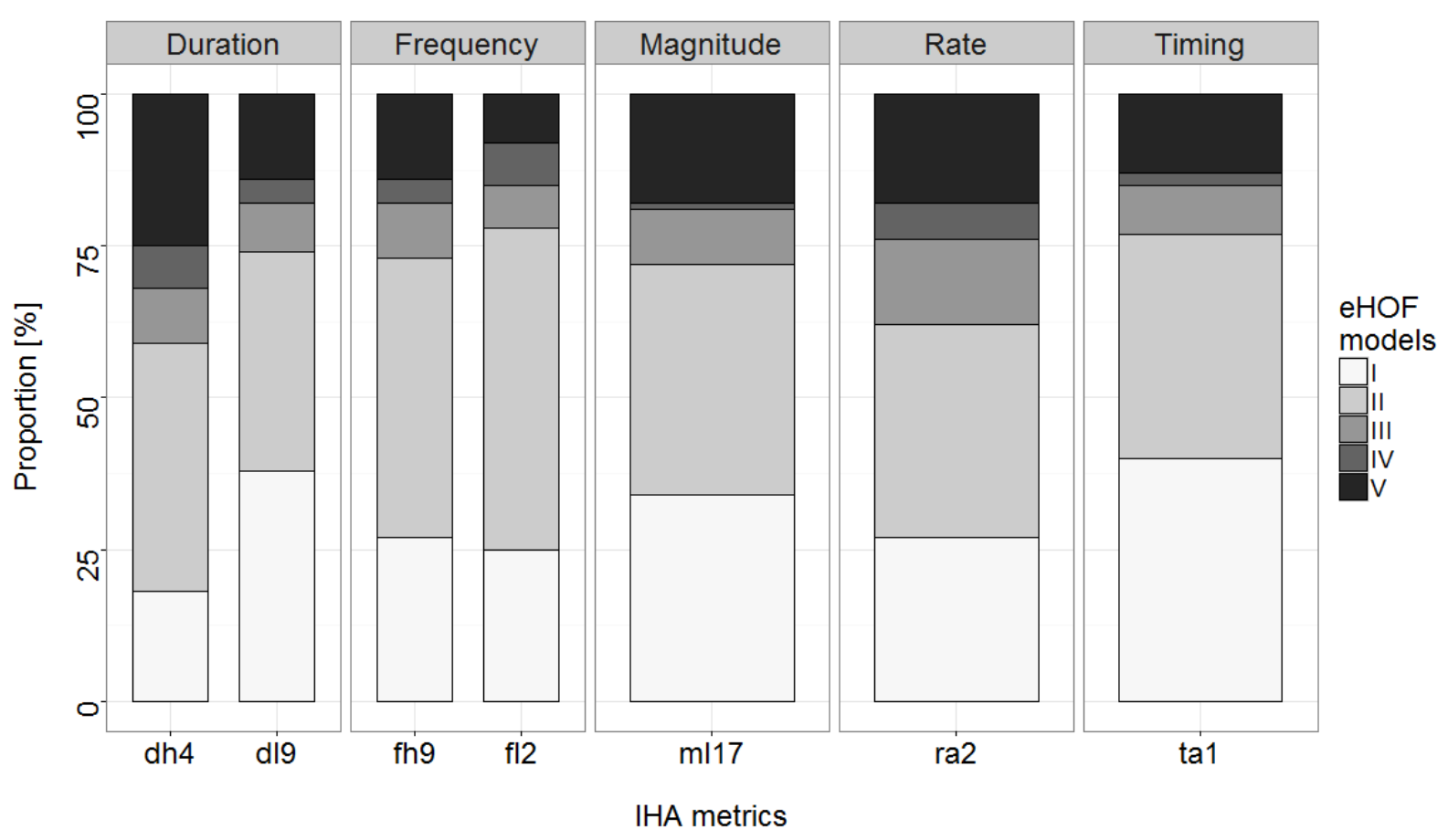

Figure 3 Model frequencies and responses of taxa to selected IHA metrics (abbreviations in Table 4). 


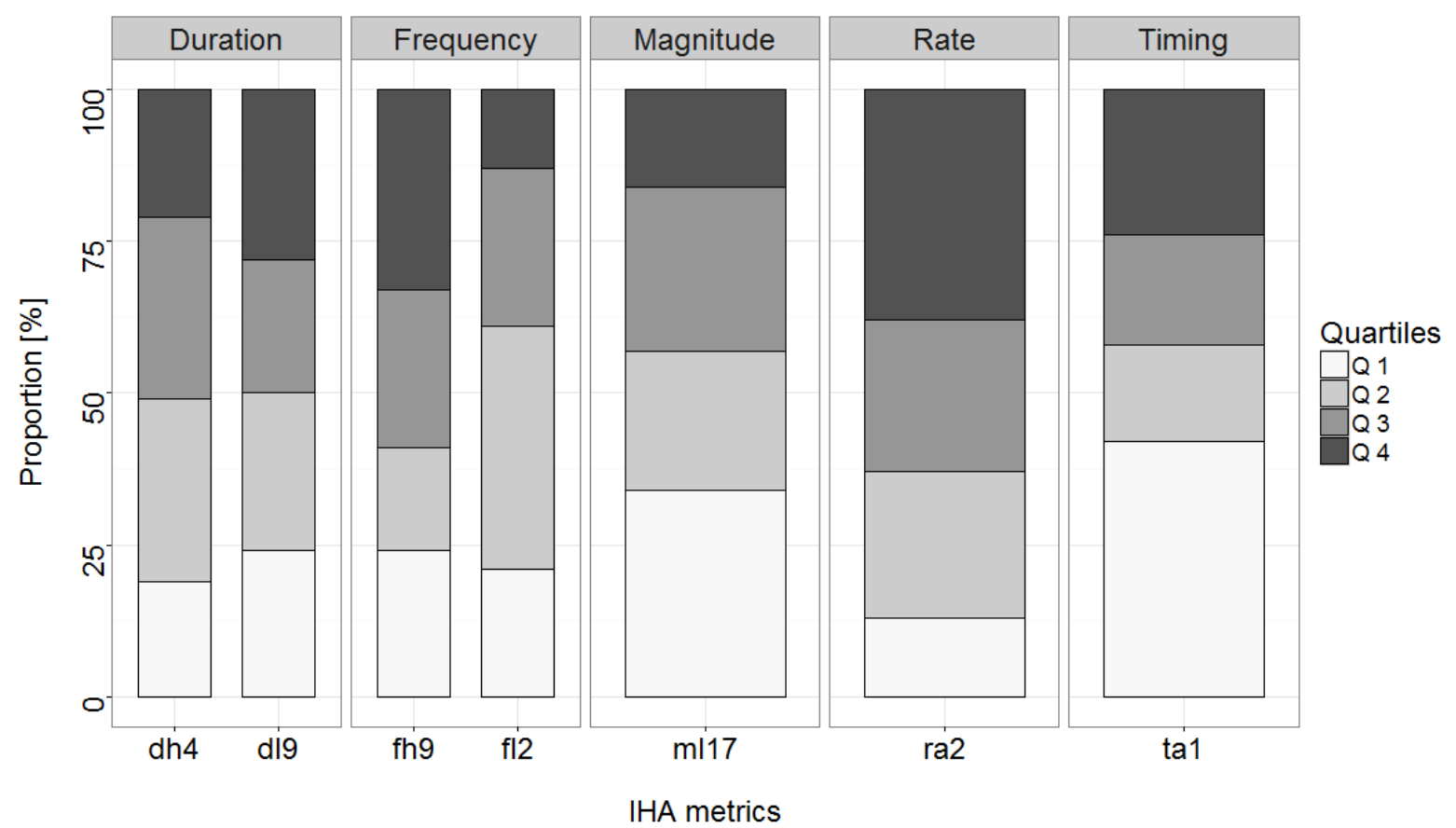

IHA metrics

Figure 4 Quartiles along the hydrological gradient where the taxa responses were strongest (i.e., location of optimum) according to the "interval optimum", "symmetrical" and "skewed" eHOF models (abbreviations in Table 4). Quartiles are shown as gray dashed lines in Figure 4.

In contrast, fl2 (frequency of low flow event, $70 \%$ ) and ta1 (timing of average flow event, $59 \%$ ) include high proportions of positive trends in monotone in-/decreasing model outcomes, revealing preferences for high values along the gradient of variability in low pulse count (Table 5).

For taxa with an interval optimum model, fh9 (frequency of high flow event, $100 \%$ ) and dh4 (duration of high flow event, $73 \%$ ) have the highest proportion of negative trends, while ml17 (magnitude of low flow event, $82 \%$ ) and tal (timing of average flow event, $78 \%$ ) include high proportions of positive trends (Table 5).

Trichoptera had the highest proportion of taxa with the eHOF model types "interval optimum", "symmetrical" and "skewed" followed by Ephemeroptera, Coleoptera and Plecoptera taxa (Table 6), which shows their preferences for specific ranges of hydrological conditions.

The highest response of Trichoptera taxa was to dh4 (duration of high flow event, 16 taxa) followed by fh9 (frequency of high flow event, 14 taxa), while Ephemeroptera taxa responded mostly to ra2 (rate of change average event, 14 taxa) and dl9 (duration of low flow event, 8 taxa). Two Plecoptera taxa respond to fh9 (frequency of high flow event), fl2 (frequency of low flow event) and ml17 (magnitude of low flow event), while only one taxon responds to dh4 (duration of high flow event),

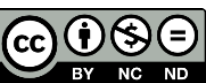


d19 (duration of low flow event), ra2 (rate of change in average event) and ta1 (timing of average flow event).

Table 4 Number and proportion of taxa with either a positive or negative trend in eHOF monotone in-/decrease or interval optimum model (abbreviations in Table 4).

\begin{tabular}{lccccccc}
\hline & dh4 & d19 & fh9 & f12 & ml17 & ra2 & ta1 \\
\hline $\begin{array}{l}\text { Number of monotone in- } \\
\text { /decreasing model outcomes }\end{array}$ & 49 & 43 & 55 & 64 & 46 & 42 & 44 \\
\hline $\begin{array}{l}\text { Percentage of positive/negative } \\
\text { trends for monotone in- }\end{array}$ & $27 / 73$ & $49 / 51$ & $42 / 58$ & $70 / 30$ & $43 / 57$ & $29 / 71$ & $59 / 41$ \\
$\begin{array}{l}\text { /decreasing model } \\
\text { Number of interval optimum }\end{array}$ & 11 & 10 & 11 & 8 & 11 & 17 & 9 \\
$\begin{array}{l}\text { model outcomes } \\
\text { Percentage of positive/negative } \\
\text { trends for interval optimum } \\
\text { model }\end{array}$ & $27 / 73$ & $40 / 60$ & $0 / 100$ & $38 / 62$ & $82 / 18$ & $53 / 47$ & $78 / 22$ \\
\hline
\end{tabular}

\subsubsection{Hydrological thresholds}

A strong decrease to nearly zero in taxa occurrence probabilities occurs if dh4 (duration of high flow event) reaches values of either greater than four (i.e., $50 \mathrm{~m}^{3} / \mathrm{s}$ prior to $\log$ transformation) or less than one (i.e., $1.7 \mathrm{~m}^{3} / \mathrm{s}$ prior to $\log$ transformation) as the maximum flow duration. Three taxa with interval optimum models showed the highest occurrence probability for "duration of high flow event" $>4$ (red arrows mark these change points; Figure 4a).

313 Remarkable reductions in the probabilities of taxa occurrence were recorded for other hydrological metrics, as well (red arrows for strong reductions; Figure 4b-g). A reduction was recorded at values greater than $80 \%$ coefficient of variation (CV) of dl9 (duration of low flow event), the magnitude of minimum annual 30-day flows (Figure 4b). This threshold for fh9 (frequency of high flow event) was more than 13, with the annual high flow events being above the threshold equal to the 75 -percent exceedance value. Taxa preferences for ranges of ml17 (magnitude of low flow event) were substantially reduced by values less than 0.4, describing a very low base flow index (Figure 4e). Constancy values of greater than 0.8 for ta1 (timing of average flow event) are also not preferred by 321 the taxa (Figure 4g). 

Focusing on specific models, none of taxa with an interval optimum model tolerated a mean number of annual high flow events larger than 12, and all preferred fewer than 9 according to dh4 (green curly bracket; Figure 4c-III). Taxa with a skewed model highly prefer quartile four of fh9 (frequency of high flow events) with gradient values between 8 and 13 (blue curly bracket; Figure 4c-V). The probability of taxa occurrence increases at low flow magnitudes $>0.4$ (Figure $4 \mathrm{e}-\mathrm{III}$ ), but several taxa with a skewed model preferred the values in quartile one based on this hydrological metric (green curly bracket; Figure 4e-V). Almost all taxa with skewed models had an optimum in the fourth quartile for ra2 (rate of change average event), which means they tolerate wide ranges of rise rates (green curly bracket; Figure 4f-V). The gradient values of these thresholds are shown in Table ST1 for individual taxa.

Table 5 Proportion (\%) of taxa from major orders and all others as "Rest" that respond to hydrological metrics with interval optimum, symmetrical or skewed model types. Taxa with a flat response model or monotone in-/decreasing model are not included due to their flat or nearly zero responses along the hydrological gradients (abbreviations in Table 4).

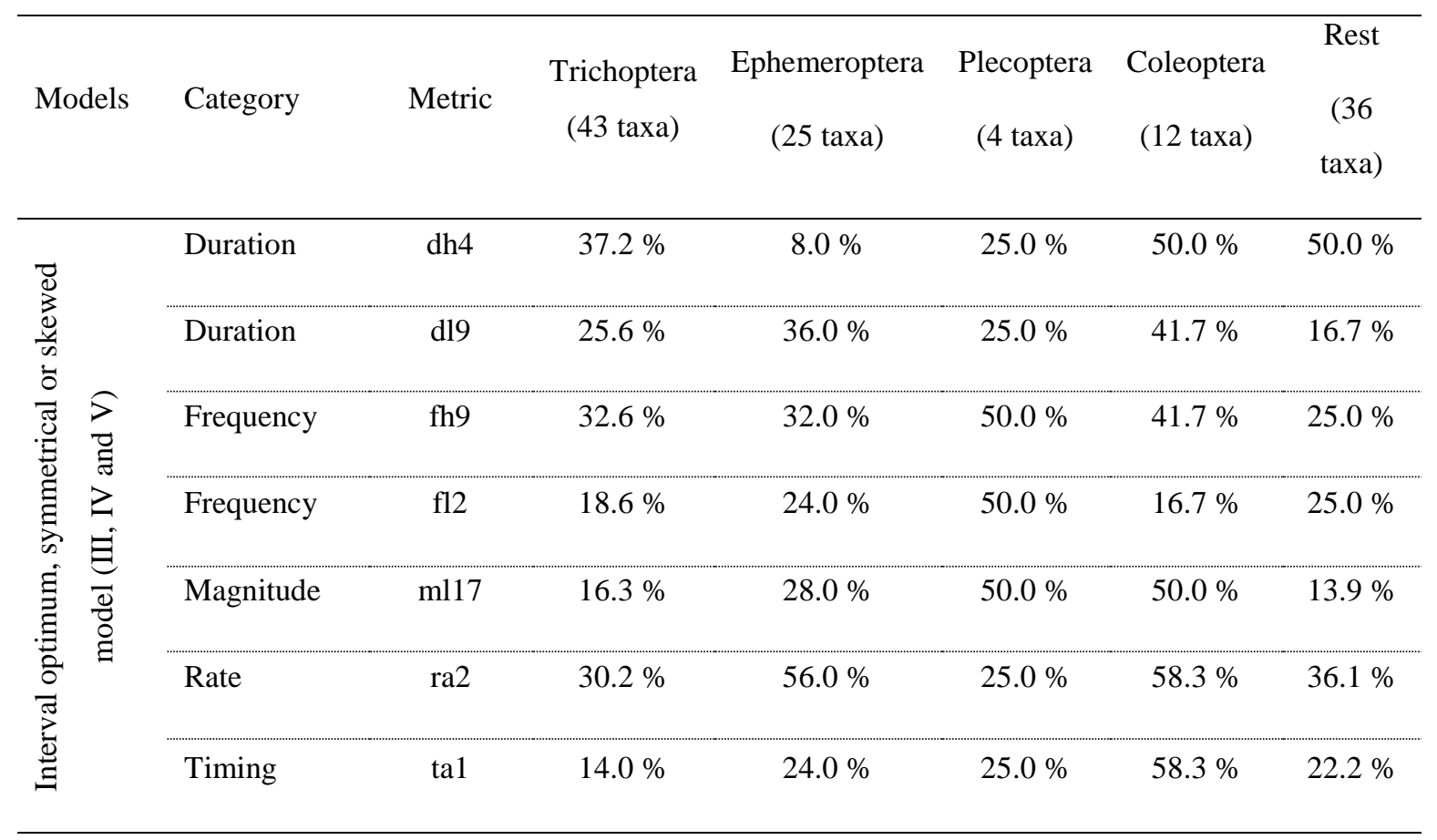

\subsubsection{Hydrological metrics}

We used 12 months of continuous daily discharge data antecedent to each individual benthic 337 invertebrate sampling date to compute IHA metrics describing the hydrological 
conditions at each sampling site. The short-term hydrological conditions prior to biological sampling are important in the occurrences and diversity of individual taxa and describe any changes according to recent hydrological conditions (Stewart-Koster et al., 2011). The calculation of IHA metrics based on very long periods of discharge and continuous biological data are more of interest if focusing on historical adaptations and long-term changes in assemblages of benthic invertebrates (Leigh and Datry, 2016).

\subsubsection{Taxa responses to metrics and along the range of hydrological gradients}

A variety of taxa responses to recent hydrological conditions were revealed. Our analysis determined the analytical optimum of taxa to seven hydrological metrics according to individual modelling responses per taxon. Taxa for which the flat response model was selected can be considered ubiquitous, as these taxa have no clear optima or preferences along the hydrological gradients. Taxa for which the symmetrical or skewed model (and potentially the interval optimum model) was chosen, showed clear responses to specific ranges of the hydrological gradients. They might cope with changes in that range compared to changes at the gradient ends, where the probability of occurrence is lower. Our results of the model frequency analysis (Figure 5) show that taxa responded more often to metrics describing high flow magnitudes and frequencies rather than low flows and to other metrics such as ra2 (rate of change in average event). These results are in concordance with other studies that reported strong influences of high flow conditions on species of benthic invertebrates (Clausen and Biggs, 1997; Death and Winterbourn, 1995; Suren and Jowett, 2006).

We covered wide ranges of quantified hydrological conditions, while previous semi-quantitative studies have covered limited ranges of flow conditions at the reach scale due to their methodology and data availability, e.g., the FST-hemispheres that were introduced by Statzner et al. (1988). The existing qualitative or semi-quantitative data described at the nominal or ordinal scales (Schmedtje, 1995; Schmidt-Kloiber and Hering, 2015) are barely comparable with the quantitative hydrological traits of benthic invertebrates and responses of taxa and thresholds along the hydrological gradients evaluated here. However, there are ecologically meaningful links between the ecological and hydrological preferences of taxa. For example, the taxa showing a clear negative response to high flows (e.g. dh4, fh9 and ra2) are prone of drifting by high flows as taxa respond to hydrological and hydraulic stress (Statzner and Holm, 1982). Anabolia nervosa and Pisidium subtruncatum show negative responses to metrics describing high flows, and preferably occur in standing waters and avoid current (SchmidtKloiber and Hering, 2015 and references therein); therefore, may be prone of being affected by higher high flows. Besides, taxa showing a clear negative response to low flows (e.g. d19, fl2 or ml17) have a high oxygen demand, and hence are vulnerable to extreme low flow conditions in summer related to high water temperature and low oxygen content (Brooks et al., 2011). Habroleptoides confusa, 
responses to metrics describing low flow conditions, and preferably occur in streams with moderate to high current (Schmidt-Kloiber and Hering, 2015 and references therein), thus may be prone of being affected by low flow conditions.

The "duration of high flow event" (dh4) describes the amount of discharge a taxon might tolerate over a period of maximum 30-day moving average flows. This metric therefore describes the river size at which discharge is larger in rivers compared to streams and within the same river size the point at which it is larger for more dynamic flow regimes compared to those that are more monotonous. This reflects the river continuum concept, i.e., some taxa prefer to inhabit upstream areas of small streams, while others prefer larger streams or rivers (Vannote et al., 1980). The ecological trait of "stream zonation preference" (freshwaterecology.info, Schmidt-Kloiber and Hering, 2015) may describe taxa hydrological preferences to dh4 (duration of high flow event) best. However, the information is available for only 88 of 120 taxa. The quantitative responses of more than $90 \%$ of 88 taxa make sense ecologically and fit to the expert judgment in the freshwater ecology database. For example, all taxa with a "flat response model" are marked as having preferences to almost all categories of "stream zonation preference". Baetis buceratus, Baetis muticus and Glossiphonia complanata are indicator taxa that occur in almost all categories and show a flat response along the range of "duration of high flow event". The inconsistencies for less than $10 \%$ of the taxa might be due to data deficiencies or methodological constraints.

The information on the ecological traits of stream benthic invertebrates is lacking for dozens of taxa, which hinders the description of their ecological and hydrological requirements; however, we successfully determined quantitative hydrological requirements for all studied taxa.

\subsubsection{Hydrological thresholds}

Both very high and very low flow conditions influence the abundances of benthic invertebrates in river ecosystems (Dewson et al., 2007b; Suren and Jowett, 2006). Although the gradient ends of hydrological metrics are not well suited for taxa, all taxa show strong responses to the first or fourth quartile of hydrological metrics (e.g., taxa with a skewed model; Figure 5). High values of maximum flow duration render taxa unable to resist against flow and drift downstream as a result (Lake, 1990).

Moreover, high gradient values of $\mathrm{dl} 9$ (duration of low flow event) and low gradient values of ml17 (magnitude of low flow event) are not suitable for taxa, as critical thresholds of low flows might be reached (Acuna et al., 2005), which are associated with high water temperatures and linked with low dissolved oxygen concentrations (Brooks et al., 2011).

Global change might potentially affect taxa by leading to changes in flow regime and discharge conditions in similar ranges of the gradient affecting some taxa. A vulnerability analysis of taxa 406 according to their hydrological thresholds requires high-resolution hydrological data 
from climate change hydrological models. Quantitative hydrological traits are therefore suitable information for modelling and predicting the effects of flow changes due to global change.

\subsubsection{Methodological constraints}

The hydrological metrics are inherently co-correlated (Olden and Poff, 2003). We aimed to analyze taxa responses to each IHA category; therefore, at least one metric per category was selected as being representative for that specific hydrological feature, resulting in seven metrics from five IHA categories. The seven selected metrics are representative of many other metrics of the same group. Even in this highly reduced set of metrics, some correlation occurs, for example, dh4 (the annual maximum 30-day moving average flows, duration of high flow event) is highly correlated with d19 (annual minimum 30-day moving average flows) with a pairwise correlation value of negative one (|r| $=-1$ ). Therefore, taxa responses cannot be judged as unique with certainty, and a currently unknown proportion of taxa could respond to either metric.

Taxa with monotone in-/decreasing model show a preference - through an increasing or decreasing trend - to either low or high values along the range of hydrological metrics with the analytical optimum at the gradient end. Taxa with an interval optimum model also have a threshold at which the occurrence probabilities increase/decrease drastically with a plateau at the upper level. The decreasing limb of taxa with this model is missing. However, these models are extremely sensitive at the gradient ends and can be affected even by a single data point (Jansen and Oksanen, 2013). This implies that the hydrological range of the respective taxa is probably not fully covered in the data.

Taxa responses vary across life stages (Lancaster and Downes, 2010a). Biological sampling at only one specific time of the year results in invertebrate species at a specific stage in their life cycle being represented. This might affect the integrity of the determination of taxa responses to hydrological conditions (Lancaster and Downes, 2010a; Lancaster et al., 2009). Although we used benthic invertebrate sample data from two seasons over a 10-year period, our dataset cannot fully overcome this difficulty, as data on all life stages of the life cycle are not available through the standard biomonitoring procedure.

The in-situ probability of taxa occurrences depends on many environmental variables. In particular, land use, habitat availability and water quality are known to be influential even over long periods of time (Allan, 2004; Harding et al., 1998). Although the range of hydrological conditions was wellcovered by the rich biological data from sampling sites with good or high ecological status, other environmental variables might still influence taxa occurrences (Stoll et al., 2016; Tonkin et al., 2016). Furthermore, suitable data for ecological processes such as competition are lacking, and these processes were not considered in this study. 
Evolved traits enable benthic invertebrates to survive flow conditions within the context of natural flow regimes (Lytle and Poff, 2004), and the abundance and structure of their communities are believed to be significantly affected by changing hydrological conditions (Sousa, 1984). Global change is influencing all aspects of the flow regime in space and over time, causing, e.g., an increase in extremely low or high flow conditions (IPCC, 2007, 2014). Germany is also facing the impacts of global change-induced flow alteration, with low and high flow conditions projected to occur more often (Nilson, 2014), which affect the distribution and probability of occurrence of several taxa. As ecological processes and the abundance and distribution of aquatic invertebrates are strongly influenced by the actual type of flow regime (Poff et al., 1997), the benthic invertebrate community will respond to flow alteration by changes in their diversity and abundance (Arthington et al., 2006; Brooks et al., 2011; Poff and Zimmerman, 2010) as well as by plasticity and adaptations (Stoks et al., 2014).

\subsubsection{Summary and outlook}

Our study represents a shift from existing studies on ecological traits, which are based on largely qualitative data and often grounded in expert knowledge and literature analysis, to describing hydrological traits, which are quantitative and data-based. However, these quantitative hydrological traits do not replace the categories of ecological traits that are linked to hydrology, e.g., resistance/resilience to droughts (Schmidt-Kloiber and Hering, 2015), but preferentially append new categories that might be useful for forecasting changes.

The quantified hydrological traits of individual taxa might therefore support stream management and enable the prediction of taxa responses to flow alteration. Such large-scale studies of flow preferences for modelling individual taxa responses to hydrological gradients can be implemented to optimize taxon-specific hydrological models.

The hydrological traits of stream benthic invertebrates may be used in forecasting studies in central Europe, and the methods used in this study are suitable for application in other regions, where a different flow regime might suggest the need to analyze other flow metrics. Other hydrological traits, e.g., those regarding extreme events, could also be modelled depending on research questions and interests.

\section{Acknowledgements}

This study was funded through the "GLANCE" project (Global Change Effects in River Ecosystems; 01 LN1320A) supported by the German Federal Ministry of Education and Research (BMBF). We thank the German Working Group on Water Issues of the Federal States and the Federal Government (LAWA) for providing the biomonitoring data and German federal state environmental agencies for providing high quality discharge data. 


\section{References}

Acuna, V., Munoz, I., Giorgi, A., Omella, M., Sabater, F., Sabater, S., 2005. Drought and postdrought recovery cycles in an intermittent Mediterranean stream: structural and functional aspects. Journal of the North American Benthological Society 24, 919-933.

Allan, J.D., 2004. Landscapes and riverscapes: the influence of land use on stream ecosystems. Annual review of ecology, evolution, and systematics, 257-284.

Archfield, S.A., Kennen, J.G., Carlisle, D.M., Wolock, D.M., 2014. An objective and parsimonious approach for classifying natural flow regimes at a continental scale. River Research and Applications 30, 1166-1183.

Armanini, D.G., Horrigan, N., Monk, W.A., Peters, D.L., Baird, D.J., 2011. Development of a Benthic Macroinvertebrate Flow Sensitivity Index for Canadian Rivers. River Research and Applications 27, 723-737.

Arthington, A.H., Bunn, S.E., Poff, N.L., Naiman, R.J., 2006. The challenge of providing environmental flow rules to sustain river ecosystems. Ecological Applications 16, 1311-1318. Bellard, C., Bertelsmeier, C., Leadley, P., Thuiller, W., Courchamp, F., 2012. Impacts of climate change on the future of biodiversity. Ecology Letters 15, 365-377.

Brooks, A.J., Chessman, B.C., Haeusler, T., 2011. Macroinvertebrate traits distinguish unregulated rivers subject to water abstraction. Journal of the North American Benthological Society 30, 419-435.

Bunn, E.S., Arthington, H.A., 2002. Basic Principles and Ecological Consequences of Altered Flow Regimes for Aquatic Biodiversity. Environmental Management 30, 492-507.

Clausen, B., Biggs, B., 1997. Relationships between benthic biota and hydrological indices in New Zealand streams. Freshwater biology 38, 327-342.

Death, R.G., 2008. The effect of floods on aquatic invertebrate communities. Aquatic insects: challenges to populations, 103-121.

Death, R.G., Winterbourn, M.J., 1995. Diversity patterns in stream benthic invertebrate communities: the influence of habitat stability. Ecology 76, 1446-1460.

DeWeber, J.T., Wagner, T., 2014. A regional neural network ensemble for predicting mean daily river water temperature. Journal of Hydrology 517, 187-200.

Dewson, Z.S., James, A.B.W., Death, R.G., 2007. A review of the consequences of decreased flow for instream habitat and macroinvertebrates. Journal of the North American Benthological Society 26, 401-415.

Dormann, C.F., Elith, J., Bacher, S., Buchmann, C., Carl, G., Carre, G., Marquez, J.R.G., Gruber, B., Lafourcade, B., Leitao, P.J., Munkemuller, T., McClean, C., Osborne, P.E., Reineking, B., Schroder, B., Skidmore, A.K., Zurell, D., Lautenbach, S., 2013. Collinearity: a review of methods to deal with it and a simulation study evaluating their performance. Ecography 36 , 27-46.

Dunbar, M.J., Pedersen, M.L., Cadman, D., Extence, C., Waddingham, J., Chadd, R.P., Larsen, S.E., 2010a. River discharge and local-scale physical habitat influence macroinvertebrate LIFE scores. Freshwater Biology 55, 226 - 242.

Gittleman, J.L., Kot, M., 1990. Adaptation: Statistics and a Null Model for Estimating Phylogenetic Effects. Systematic Zoology 39, 227-241.

Hale, A.N., Noble, G., Piper, K., Garmire, K., Tonsor, S.J., 2016. Controlling for hydrologic connectivity to assess the importance of catchment-and reach-scale factors on macroinvertebrate community structure. Hydrobiologia 763, 285-299. 
Harding, J., Benfield, E., Bolstad, P., Helfman, G., Jones, E., 1998. Stream biodiversity: the ghost of land use past. Proceedings of the national academy of sciences 95, 14843-14847. Heino, J., Soininen, J., 2010. Are common species sufficient in describing turnover in aquatic metacommunities along environmental and spatial gradients? Limnology and Oceanography 55, 2397-2402.

Henriksen, J.A., Heasley, J., Kennen, J.G., Niewswand, S., 2006. Users' manual for the Hydroecological Integrity Assessment Process software (including the New Jersey Assessment Tools): U.S. Geological Survey Open-File Report. 1093 - 2006.

Huisman, J., Olff, H., Fresco, L., 1993. A hierarchical set of models for species response analysis. Journal of Vegetation Science 4, 37-46.

IPCC, 2007. Climate Change 2007: The Physical Science Basis. Contribution of Working Group I to the Fourth Assessment Report of the Intergovernmental Panel on Climate Change, in: S. Solomon, D.Q., M. Manning, Z. Chen, M. Marquis, K.B. Averyt, M. Tignor, H.L. Miller (Ed.). Cambridge University Press., Cambridge, United Kingdom and New York, NY, USA.

IPCC, 2014. Climate Change 2014: Synthesis Report. Contribution of Working Groups I, II and III to the Fifth Assessment Report of the Intergovernmental Panel on Climate Change, in: R.K. Pachauri, Meyer, L.A. (Eds.). IPCC, Geneva, Switzerland, p. 151pp.

Jansen, F., Oksanen, J., 2013. How to model species responses along ecological gradients Huisman-Olff-Fresco models revisited. Journal of Vegetation Science 24, 1108-1117.

Konrad, C.P., Brasher, A.M.D., May, J.T., 2008. Assessing streamflow characteristics as limiting factors on benthic invertebrate assemblages in streams across the western United States. Freshwater Biology 53, 1983-1998.

Lake, P.S., 1990. effects of successive flow perturbations on stream invertebrates. Australian Journal of Ecology 15, 477 - 488.

Lancaster, J., Downes, B.J., 2010. Ecohydraulics needs to embrace ecology and sound science, and to avoid mathematical artefacts. River Research and Applications 26, 921-929.

Lancaster, J., Downes, B.J., Glaister, A., 2009. Interacting environmental gradients, trade-offs and reversals in the abundance-environment relationships of stream insects: when flow is unimportant. Marine and Freshwater Research 60, 259-270.

Leigh, C., Datry, T., 2016. Drying as a primary hydrological determinant of biodiversity in river systems: a broad-scale analysis. Ecography, n/a-n/a.

Lobo, J.M., Tognelli, M.F., 2011. Exploring the effects of quantity and location of pseudoabsences and sampling biases on the performance of distribution models with limited point occurrence data. Journal for Nature Conservation 19, 1-7.

Lytle, D.A., Poff, N.L., 2004. Adaptation to natural flow regimes. Trends in Ecology \& Evolution 19, 94-100.

Monk, W.A., Wood, P.J., Hannah, D.M., Wilson, D.A., 2007. Selection of river flow indices for the assessment of hydroecological change. River Research and Applications 23, 113-122.

Monk, W.A., Wood, P.J., Hannah, D.M., Wilson, D.A., Extence, C.A., Chadd, R.P., 2006. Flow variability and macroinvertebrate community response within riverine systems. River Research and Applications 22, 595-615.

Nilson, E., 2014. Auswirkungen des Klimawandels auf das Abflussgeschehen und die Binnenschifffahrt in Deutschland: Schlussbericht KLIWAS-Projekt 4.01. Bundesanstalt für Gewässerkunde.

Olden, J.D., Poff, N.L., 2003. Redundancy and the choice of hydrologic indices for characterizing streamflow regimes. River Research and Applications 19, 101-121. 
Poff, N.L., Allan, J.D., Bain, M.B., Karr, J.R., Prestegaard, K.L., Richter, B.D., Sparks, R.E., Stromberg, J.C., 1997. The natural flow regime. Bioscience 47, 769-784.

Poff, N.L., Julie Zimmerman, K.H., 2010. Ecological responses to altered flow regimes: a literature review to inform the science and management of environmental flows. Freshwater Biology 55, 194-205.

Poff, N.L., Olden, J.D., Merritt, D.M., Pepin, D.M., 2007. Homogenization of regional river dynamics by dams and global biodiversity implications. Proceedings of the National Academy of Sciences 104, 5732-5737.

Principe, R.E., Raffaini, G.B., Gualdoni, C.M., Oberto, A.M., Corigliano, M.C., 2007. Do hydraulic units define macroinvertebrate assemblages in mountain streams of central Argentina? Limnologica 37 323-336.

Schmedtje, U., 1995. Ökologische Grundlagen für die Beurteilung von Ausleitungsstrecken. Beziehung zwieschen der sohnlnahen Strömung, dem Gewässerbett und dem Makrozoobenthos in Fließgewässern. Informationsberichte des Bayerischen Landesamtes für Wasserwirtschaft, Heft 25.

Schmedtje, U., Sommerhäuser, M., Braukmann, U., Briem, E., Haase, P., Hering, D., 2000. Top-down. Konzept einer biozönotisch begründeten Fließgewässertypologie Deutschlands. In: Deutsche Gesellschaft für Limnologie (Hrsg.): Tagungsbericht, 147-151.

Schmidt-Kloiber, A., Hering, D., 2015. www.freshwaterecology.info - An online tool that unifies, standardises and codifies more than 20,000 European freshwaterorganisms and their ecological preferences. Ecological Indicators 53, 271-282.

Sousa, W.P., 1984. The role of disturbance in natural communities. Annual review of ecology and systematics $15,353-391$.

Statzner, B., Gore, J.A., Resh, V.H., 1988. Hydraulic Stream Ecology - Observed Patterns and Potential Applications. Journal of the North American Benthological Society 7, 307-360.

Statzner, B., Holm, T.F., 1982. Morphological adaptations of benthic invertebrates to stream flow-an old question studied by means of a new technique (Laser Doppler Anemometry). Oecologia 53, 290-292.

Stewart-Koster, B., Olden, J., Kennard, M.J., Pusey, B.J., Boone, E., Douglas, M., Jackson, S., 2011. Fish response to the temporal hierarchy of the natural flow regime in the Daly River, northern Australia. Journal of Fish Biology 79, 1525-1544.

Stoks, R., Geerts, A.N., De Meester, L., 2014. Evolutionary and plastic responses of freshwater invertebrates to climate change: realized patterns and future potential. Evolutionary applications 7, 42-55.

Stoll, S., Breyer, P., Tonkin, J.D., Früh, D., Haase, P., 2016. Scale-dependent effects of river habitat quality on benthic invertebrate communities-Implications for stream restoration practice. Science of the Total Environment 553, 495-503.

Suren, A.M., Jowett, I.G., 2006. Effects of floods versus low flows on invertebrates in a New Zealand gravel-bed river. Freshwater Biology 51, 2207-2227.

Team, R.C., 2016. R: A language and environment for statistical computing. R Foundation for Statistical Computing, Vienna, Austria. 2015. URL h ttp. www. R-project. org. Tonkin, J.D., Stoll, S., Jähnig, S.C., Haase, P., 2016. Anthropogenic land-use stress alters community concordance at the river-riparian interface. Ecological Indicators 65, 133-141. VanDerWal, J., Shoo, L.P., Graham, C., Williams, S.E., 2009. Selecting pseudo-absence data for presence-only distribution modeling: How far should you stray from what you know? Ecological Modelling 220, 589-594. 
611 Vannote, R.L., Minshall, G.W., Cummins, K.W., Sedell, J.R., Cushing, C.E., 1980. The river 612 continuum concept. Canadian journal of fisheries and aquatic sciences 37, 130-137.

613 